26. Czerny M, Schmidli J, Adler S, van den Berg JC, Bertoglio L, Carrel T, et al. Current options and recommendations for the treatment of thoracic aortic pathologies involving the aortic arch: an expert consensus document of the European Association for Cardio-Thoracic surgery (EACTS) and the European Society for Vascular Surgery (ESVS). Eur J Cardiothorac Surg. 2019;55:133-62.

27. Rylski B, Pérez M, Beyersdorf F, Reser D, Kari FA, Siepe M, et al. Acute non-A non-B aortic dissection: incidence, treatment and outcome. Eur J Cardiothorac Surg. 2017;52:1111-7.
28. Nauta FJ, Tolenaar JL, Patel HJ, Appoo JJ, Tsai TT, Desai ND, et al. Impact of retrograde arch extension in acute type B aortic dissection on management and outcomes. Ann Thorac Surg. 2016;102:2036-43.

29. Loewe C, Czerny M, Sodeck GH, Ta J, Schoder M, Funovics M, et al. A new mechanism by which an acute type B aortic dissection is primarily complicated, becomes complicated, or remains uncomplicated. Ann Thorac Surg. 2012;93:1215-22.

30. Weiss G, Wolner I, Folkmann S, Sodeck G, Schmidli J, Grabenwöer M, et al. The location of the primary entry tear in acute type B aortic dissection affects early outcome, Eur J Cardiothorac Surg. 2012:42:571-6.
See Article page 958.

\section{Commentary: Medically managed uncomplicated descending thoracic aortic dissection: Are we gambling?}

\author{
Luca Di Marco, $\mathrm{MD}, \mathrm{PhD},{ }^{\mathrm{a}}$ and \\ Michele Di Mauro, MD, PhD, MSc ${ }^{\mathrm{b}}$
}

"I believe that we do not know anything for certain, but everything probably"

Christian Huygens, XVII century

Christian Huygens (April 14, 1629 to July 8, 1695) was a Dutch physicist, mathematician, astronomer, and inventor who is widely considered one of the greatest scientists of all time and a major figure in the so-called "scientific revolution." As a mathematician, Huygens developed the theory of probability, and in 1657 he wrote his first treatise on the probability theory, "De ratiociniis in ludo aleae," presenting a systematic study on probability dealing with games of chance and the odds associated with all gaming

\footnotetext{
From the a Division of Cardiac Surgery, IRCCS, S Orsola Hospital, Azienda Ospedaliero-Universitaria di Bologna, Bologna, Italy; and ${ }^{\mathrm{b}}$ Cardio-Thoracic Surgery Unit, Heart and Vascular Centre, Maastricht University Medical Centre, Cardiovascular Research Institute Maastricht, Maastricht, The Netherlands.

Disclosures: The authors reported no conflicts of interest.

The Journal policy requires editors and reviewers to disclose conflicts of interest and to decline handling or reviewing manuscripts for which they may have a conflict of interest. The editors and reviewers of this article have no conflicts of interest.

Received for publication April 13, 2021; revisions received April 13, 2021; accepted for publication April 15, 2021; available ahead of print April 20, 2021

Address for reprints: Michele Di Mauro, MD, PhD, MSc, Cardio-Thoracic Surgery Unit, Heart and Vascular Centre, Maastricht University Medical Centre, Cardiovascular Research Institute Maastricht, P Debyelaan 25, 6202 AZ Maastricht, The Netherlands (E-mail: mdimauro1973@gmail.com).

J Thorac Cardiovasc Surg 2023;165:969-70

$0022-5223 / \$ 36.00$

Copyright (C) 2021 by The American Association for Thoracic Surgery

https://doi.org/10.1016/j.jtcvs.2021.04.035
}

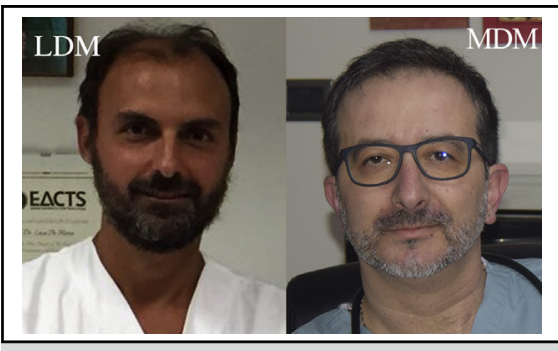

Luca Di Marco, MD, PhD, and Michele Di Mauro, MD, PhD, MSc

\section{CENTRAL MESSAGE}

The authors identify the anatomic characteristics of patients undergoing late aortic interventions and the predictive risk factors for aortic interventions.

events. Huygens' theories and subsequent use of expectation values are considered the basis of the modern concept of probability. ${ }^{1}$

An analogy may very well be found between Huygens' aphorism and the conclusions traced within this study, conducted by one of the leading European centers of aortic open and endovascular surgery. The authors, in fact, seem to demonstrate what Huygens claimed: just as in gambling, nothing is known with certainty, but everything is determined with probability. In medicine, even if there are no certainties, it is possible to estimate the odds that certain events may actually occur.

Acute uncomplicated type B aortic dissection (TBAD) treated with medical therapy is a field with some open issues, which Kreibich and colleagues aimed to address with their retrospective study. ${ }^{2}$ Historically, the gold standard therapeutic option for acute uncomplicated TBAD has been aggressive medical therapy to achieve an 
optimal heart rate and blood pressure control to reduce shear stress on the dissected segment of the aorta. However, recent data show that a significant proportion of patients with acute uncomplicated TBAD discharged with medical therapy have late aorta-related complications that increase mortality and often necessitate urgent surgical or endovascular intervention. ${ }^{3,4}$

In this study, Kreibich and colleagues provide clear answers to questions concerning the identification of risk factors for late aortic interventions and evaluate the outcomes of endovascular, hybrid, and open surgical treatment in patients with initial uncomplicated acute TBAD treated with medical therapy. Through a retrospective analysis over a 7-year period, they evaluate the outcomes of 91 patients diagnosed with acute uncomplicated TBAD treated with medical therapy who are discharged further to computed tomography angiography (angioCT). Follow-up (FU) care was duly performed by means of angioCT after 6 months, 12 months, and then annually at each FU visit and whenever mandated by the patient's clinical condition. The mean duration of FU was 44 months, and during the study period, $33 \%$ of patients initially admitted with acute uncomplicated TBAD and discharged with medical therapy required an aortic procedure (endovascular, open surgery, or hybrid) by only 4 months after discharge. ${ }^{2}$ These interesting data show that, depending on the anatomic characteristics of the dissection, by several months after discharge, onethird of patients discharged with medical therapy require some endovascular procedure, open surgery with frozen elephant trunk or with thoracoabdominal aortic replacement, or hybrid treatment because of aortic complications.

The strength of these findings, despite the rather limited patient population, is that the authors identify the anatomic characteristics of patients undergoing late aortic interventions and the predictive risk factors for aortic interventions. Previous studies showed that the strongest independent predictors of aneurysmal growth and need for late intervention are an initial false lumen (FL) diameter of $22 \mathrm{~mm}$, a maximum aortic diameter $>40 \mathrm{~mm}$ at initial presentation, a patent or partially thrombosed FL, and an initial entry tear $\geq 10 \mathrm{~mm}^{5-7}$ In contrast, a thrombosed FL, multiple entry tears, a FL located at the outer aortic curvature, and a circular (vs elliptical) arrangement of the true lumen are associated with limited aortic growth. ${ }^{8,9}$

Kreibich and colleagues, ${ }^{2}$ on the other hand, report that patients requiring aortic intervention presented with a significantly longer aortic dissection, a completely perfused FL in descending thoracic aorta, and more reentries between the true lumen and FL. Moreover, the most proximal communication (entry tear) was significantly closer to the left subclavian artery, but the dimension of the entry tear was similar, with no difference in the location of the dissection (inner vs outer curvature) between patients with and patients without aortic interventions. Moreover, patients who have undergone aortic interventions have a significantly smaller true lumen than FL and larger diameters in the various portions of the aorta compared with patients without aortic interventions. The study also defines a dissected descending thoracic aortic diameter exceeding $45 \mathrm{~mm}$ on the diagnostic computed tomography angiography and younger age as the strongest risk factors for aortic interventions after discharge. Another important finding is that this subgroup of patients has an estimated risk of aortic interventions of $29 \%$ at 1 year and $38 \%$ at 3 years because of a $>0.5-\mathrm{cm}$ progression of aortic diameter in 1 year, clinical worsening, or, in extreme cases, aortic rupture with emergent treatment.

From the authors' experience, we can speculate on the importance of creating hub centers for acute TBAD - concentrating this subgroup of patients in a few centers with a high volume of patients and extensive experience, able to offer all possible therapeutic options to treat TBAD, emphasizing the importance of rigorous and accurate FU or early treatment for those patients who have certain anatomic features and are younger. Among the latter patients, in fact, possible connective tissue pathologies or congenital predispositions that could justify a more aggressive attitude could play an important role.

In our opinion, this study from Kreibich and colleagues ${ }^{2}$ should be seen as an effective and useful attempt to estimate the probability of aortic complications in a subgroup of patients with uncomplicated acute TBAD treated with medical therapy and to identify their risk factors for late aortic interventions. Given these conclusions, and the odds that patients with certain anatomic features will most likely, if not surely, undergo aortic interventions within an average time of 4 months after discharge, wouldn't it be safer for them to undergo early treatment right away, rather than adopting the "wait and see approach" of the so-called "uncomplicated" acute TBAD?

In our opinion, and quoting Huygens' aphorism, this is so, as this study deducts a probability allowing us to have a real "chance" at winning at this game, which without these applications would be just a gambling game.

\section{References}

1. Bell AE. Christian Huygens and the Development of Science in the Seventeenth Century. New York: Edward Arnold; 1947.

2. Kreibich M, Siepe M, Berger T, Beyersdorf F, Soschynski M, Schlett CL, et al. Intervention rates and outcomes in medically-managed uncomplicated descending thoracic aortic dissections. J Thorac Cardiovasc Surg. 2023;165:958-65.e4.

3. Durham CA, Cambria RP, Wang LJ, Ergul EA, Aranson N, Patel VI, et al. The natural history of medically managed acute type B aortic dissection. J Vasc Surg. 2015;61:1192-8.

4. Yuan X, Mitsis A, Ghonem M, Iakovakis I, Nienaber CA. Conservative management versus endovascular or open surgery in the spectrum of type B aortic dissection. J Vis Surg. 2018;4:59.

5. Schwartz SI, Durham C, Clouse WD, Patel VI, Lancaster RT, Cambria RP, et al. Predictors of late aortic intervention in patients with medically treated type B aortic dissection. J Vasc Surg. 2018;67:78-84. 
6. Song JM, Kim SD, Kim JH, Kim MJ, Kang DH, Seo JB, et al. Long-term predictors of descending aorta aneurysmal change in patients with aortic dissection. JAm Coll Cardiol. 2007;50:799-804.

7. Durham CA, Aranson NJ, Ergul EA, Wang LJ, Patel VI, Cambria RP, et al. Aneurysmal degeneration of the thoracoabdominal aorta after medical management of type B aortic dissections. J Vasc Surg. 2015;62:900-6.
8. van Bogerijen GH, Tolenaar JL, Rampoldi V, Moll FL, van Herwaarden JA, Jonker FH, et al. Predictors of aortic growth in uncomplicated type B aortic dissection. J Vasc Surg. 2014;59:1134-43.

9. Tolenaar JL, van Keulen JW, Jonker FH, van Herwaarden JA, Verhagen HJ, Moll FL, et al. Morphologic predictors of aortic dilatation in type B aortic dissection. J Vasc Surg. 2013;58:1220-5. 